\title{
Characterization of the Surface of Activated Carbons Produced from Tire Residues
}

\author{
J.M.V. Nabais ${ }^{1, a}$, C. Laginhas ${ }^{1, b}$, P.J.M. Carrott ${ }^{1, c}$, M.M.L. Ribeiro Carrott ${ }^{1, d}$, \\ C. Galacho ${ }^{1, e}$, J.E.C. Amorós ${ }^{2, f}$ and A.V.N. Gisbert ${ }^{2, g}$ \\ ${ }^{1}$ Centro de Química de Évora e Departamento de Química da Universidade de Évora \\ Rua Romão Ramalho $n^{\circ}$ 59, 7000-671 Évora, Portugal \\ ${ }^{2}$ Department of Mechanical Engineering and Materials Science \\ Polytechnic University of Valencia, Spain \\ ajvn@uevora.pt, ${ }^{b}$ carloslagilhas@gmail.com, ${ }^{\text {c }}$ peter@uevora.pt, ${ }^{d}$ manrc@uevora.pt, \\ ecg@uevora.pt, , fjocream@dimm.upv.es, ${ }^{\mathrm{g}}$ anadal@mcm.upv.es
}

Keywords: Activated carbon, Tire residues, Waste management, Surface characterization.

\begin{abstract}
The surface characterisation of new activated carbons produced from tire residues by activation with carbon dioxide was studied. The activated carbons produced were mainly basic with point of zero charge values above 8.8. The main surface functional groups identified by FTIR were ether, quinones, lactones, ketones, hydroxyls (free and phenol) and pyrones. The XRD analysis shows that the materials produced have a microstructural organisation with microcrystallite height around $1.5 \mathrm{~nm}$ and width from 3 to $5.3 \mathrm{~nm}$. This analysis indicates also the possible presence of oxides (single or mixture) of the following heteroatoms: $\mathrm{Fe}, \mathrm{Al}, \mathrm{Ca}, \mathrm{Mg}, \mathrm{Ti}, \mathrm{Si}, \mathrm{K}, \mathrm{Pb}, \mathrm{Cd}, \mathrm{Ba}, \mathrm{Zn}$ and $\mathrm{Sn}$. The results have shown the significant potential of this type of residues for activated carbon production. Furthermore, the environment friendly use of an industrial residue is also noteworthy.
\end{abstract}

\section{Introduction}

Tire residues are a significant environmental problem which affects a large part of the developed countries as dumped tires take about 100 years to fully deteriorate. It is urgent to minimise industrial residues as the planet no longer has capacity for self-regeneration which is a major problem for the next generations. At the same time reutilisation of industrial residues can create an important economic surplus. One of the most prominent methods is to reduce the residues by means of reusing them as precursors for other processes, such as the production of carbon materials. Carbon materials, and in particular activated carbons (ACs), are nowadays one of the most relevant adsorbent materials in our society and used in diverse areas of human activity. ACs are used in a wide range of applications, in both the gas and liquid phases, that include medicinal uses, gas storage, pollutants removal, gas separations, odours removal and catalysis.

Typically, used tires can be processed by retreading (the tread patterns of the tires are replaced), recycling (the rubber material from the tires is used to replace materials for a range of products and applications and to some degree for new tires) or in energy recovery (as fuel replacing other sources such as oil or coal). However, these methods don't absorb all the waste tires that are being produced every day. The European Tyre Recycling Association (ETRA) estimated that in 2007 only 33\% of the end-of-life tires were recycled into recovered materials [1].

The use of this type of precursor to produce ACs can give a valuable contribution to meet the European Union (EU) objective to abolish the landfilling of waste tires, which can only be achieved if alternative outlets, besides the usual methods, for waste tires are used. According to the European Environmental Agency in 2000 approximately $2.5 \times 10^{6}$ ton of waste tires were produced in EU Member States and about 30\% were still dumped in landfill or burnt [2]. As of 2006 the European Directives have banned scrap tires, schredded tires and tire residues from being landfilled. The Directive 2006/12/EC states that "Member States must prohibit the abandonment, dumping or uncontrolled disposal of waste, and must promote waste prevention, recycling and processing for re- 